\title{
A (DES)IGUALDADE DE CONHECIMENTO NO CICLO DE ALFABETIZAÇÃO*
}

\author{
NAIRA DA COSTA MUYLAERT LIMA \\ ALICIA MARIA CATALANO DE BONAMINO \\ LUIS ANTONIO FAJARDO PONTES
}

* Os autores agradecem o financiamento da Coordenação de Aperfeiçoamento de Pessoal de Nível Superior (Capes) Observatório da Educação, Edital n 038/2010/Capes/Inep.

\section{RESUMO}

Este trabalho busca contribuir para o debate acerca do tema das desigualdades educacionais, por meio da investigação da (re)produção da desigualdade de conhecimento. Com base nos dados da avaliação longitudinal da alfabetização do Espírito Santo, das edições de 2012, 2013 e 2014, o estudo analisou a variação do percentual de acerto entre turmas de alto e baixo desempenho nos testes de Leitura do $1^{\circ}$ e $3^{\circ}$ ano do ensino fundamental. 0 principal resultado aponta que a aquisição das habilidades é mais heterogênea no $1^{\circ}$ ano, o que permite supor que, ao longo do ciclo de alfabetização, os alunos podem ter passado por processos de reorganização intraescolar que tornaram seus resultados mais homogêneos, ou seja, menos desiguais. A despeito disso, há determinadas habilidades que não estão consolidadas até 0 fim do $3^{\circ}$ ano, o que evidencia a ineficácia das políticas atuais para fazer com que os alunos adquiram habilidades imprescindiveis ao processo de alfabetização.

PALAVRAS-CHAVE ALFABETIZAÇÃO • AVALIAÇÃO DA EDUCAÇÃO • CONHECIMENTOS • DESIGUALDADES EDUCACIONAIS. 


\title{
LA (DES)IGUALDAD DE CONOCIMIENTO EN EL CICLO DE ALFABETIZACIÓN
}

RESUMEN

Este trabajo intenta contribuir con el debate acerca del tema de las desigualdades educacionales, por medio de la investigación de la (re)producción de la desigualdad de conocimiento. En base a los datos de la evaluación longitudinal de la alfabetización del estado de Espírito Santo en las ediciones de 2012, 2013 y 2014, el estudio analizó la variación del porcentual de acierto entre grupos de alto y bajo desempeño en las pruebas de Lectura del 1er y 3er año de la educación básica. El principal resultado señala que la adquisición de las habilidades es más heterogénea en el 1er año, lo que permite suponer que, a lo largo del ciclo de alfabetización, los alumnos pueden haber pasado por procesos de reorganización intraescolar que hicieron que sus resultados fueran más homogéneos, es decir, menos desiguales. A pesar de ello, hay determinadas habilidades que no se consolidan hasta fines del 3er año, lo que pone de manifiesto la ineficacia de las actuales politicas para que los alumnos aprendan habilidades imprescindibles al proceso de alfabetización.

PALABRAS CLAVE ALFABETIZACIÓN - EVALUACIÓN DE LA EDUCACIÓN • CONOCIMIENTOS • DESIGUALDADES EDUCACIONALES.

\section{THE (IN)EQUALITY OF KNOWLEDGE IN THE LITERACY CYCLE}

\begin{abstract}
The present study seeks to contribute to the debate about educational inequalities, using the study of the (re)production of the inequality of knowledge. Based on data from the longitudinal evaluation of literacy in Espirito Santo, from the 2012, 2013 and 2014 publications, this study has analyzed the percentage of variation between the high and low performance groups in the Reading Tests of the 1st and 3rd years of high school. The main results point out that the acquisition of skills is more heterogenous in the 1st year, which supports the hypothesis that, during the literacy cycle, students may have gone through intrascholastic reorganization processes which make their results more homogeneous. That is, less unequal. Despite this, there are certain skills that are not consolidated by the end of the 3rd year, which provides evidence of the ineffectiveness of the current policies for students to learn essential skills throughout the literacy process.
\end{abstract}

KEYWORDS LITERACY • EDUCATIONAL EVALUATION • KNOWLEDGE • EDUCATIONAL INEQUALITIES. 


\section{INTRODUÇÃO}

A discussão da justiça na educação pode ser abordada à luz de três perspectivas: igualdade de oportunidades, de tratamento e de conhecimento (CRAHAY, 2002). Há tempo, as duas primeiras perspectivas são debatidas no campo da Sociologia da Educação, que relaciona desigualdades educacionais e desigualdades sociais. Mais recentemente, o conceito de igualdade de conhecimento também passou a ser incorporado às discussões acerca das desigualdades.

Crahay (2002), ao refletir sobre a justiça no âmbito da educação básica, mostra os limites das duas noções mais difundidas no campo educacional: a igualdade de oportunidade e a igualdade de tratamento. A primeira se sustenta na teoria dos dons naturais e, portanto, na garantia de condições iguais de desenvolvimento das pessoas, independentemente do nascimento, da cor e do sexo. A segunda noção, ao propor tratar os desiguais como iguais, estaria contribuindo para a reprodução das desigualdades sociais.

Para o autor (CRAHAY, 2002), embora essas noções apontem para questões pertinentes, elas são insuficientes para 
garantir a materialização de uma escola justa, ou seja, aquilo que, no Brasil, vem sendo legalmente definido como o direito público subjetivo a uma educação básica de qualidade, conforme a Constituição Federal de 1988 (Art. 208, §1).

Além disso, Crahay (2002) introduz uma nova noção, a de igualdade de conhecimentos adquiridos, como uma possibilidade para fazer avançar não apenas a discussão das relações entre desigualdades sociais e educacionais, mas também a busca pela plena igualdade de conhecimentos de base, de forma a garantir uma escola eficaz e justa.

A principal característica da igualdade de conhecimento diz respeito às formas de organização escolar que devem ter como foco o aprendizado dos conhecimentos de base por parte de todos os estudantes (CRAHAY, 2002). Nessa perspectiva, o ensino deve ser organizado e planejado em função de objetivos a serem atingidos por todos. A compreensão de que o conhecimento é um direito de todos e que cada indivíduo possui ritmos e formas diferentes de aprendizagem é o principal aspecto da Pedagogia do Domínio dos Conhecimentos (PDC), proposta por Crahay (2002). Dela decorre a necessidade de se dedicar um tempo suplementar de aprendizagem aos alunos que ainda não conseguiram consolidar os conhecimentos de base, ou seja, aqueles considerados universais e que não podem deixar de ser ensinados. Segundo Ribeiro (2014, p. 1.106), para Crahay (2002), políticas educacionais e práticas escolares baseadas na igualdade dos conhecimentos adquiridos fariam jus ao princípio de justiça corretiva no âmbito da escola e incluiriam

[...] iniciativas de discriminação positiva, tais como reforço escolar para crianças com dificuldade de aprendizagem, aulas com diversidade de práticas pedagógicas para crianças com diferentes níveis de aprendizagem, inexistência de reprovação associada a baixos desempenhos e baixa desigualdade escolar e professores mais experientes trabalhando com crianças com maiores dificuldades naquele momento. Salas heterogêneas (constituídas por alunos com maiores facilidades e dificuldades no momento), estratégias de ensino coletivas e não pautadas pela individualização da aprendizagem e foco nos objetivos de 
1 A análise do percentual dos itens não levou em consideração os dados do $2^{\circ}$ ano. Esses dados foram considerados apenas para selecionar os alunos, uma vez que o estudo observou somente o percentual de acerto dos itens dos alunos participantes de todas as ondas da avaliação do Paebes-Alfa aprendizagem também se associam a essa perspectiva, tendo em vista evidências de correlação entre elas e maiores níveis de justiça na escola.

Assim, para ser justa, a escola precisa lançar mão de ações pedagógicas que garantam o aprendizado e a máxima igualdade de conhecimento entre os alunos, de forma a tornar a variação dos resultados escolares a menor possível. Para isso, a escola deveria nortear suas ações ancorando-se nos princípios da igualdade de conhecimento (CRAHAY, 2002).

O presente estudo investiga como se apresenta e como evolui a igualdade de conhecimentos adquiridos nos primeiros anos escolares, relativos ao ciclo de alfabetização. Para tanto, faz uso de dados das edições de 2012, 2013 e $2014^{1}$ do Programa de Avaliação da Educação Básica do Espírito Santo voltado para a alfabetização - Paebes-Alfa - e analisa o percentual médio de acerto dos itens difíceis de Leitura e sua variação nos testes aplicados aos alunos do $1^{\circ}$ e $3^{\circ}$ ano do ensino fundamental (EF), em turmas de alto e baixo desempenho.

Implementado em 2008, o Paebes-Alfa aplica testes de Leitura, Escrita e Matemática aos alunos dos três primeiros anos do ensino fundamental. Trata-se de uma avaliação com desenho longitudinal, que permite verificar a evolução do aprendizado dos mesmos alunos ao longo dos três anos do ciclo de alfabetização.

A avaliação dos anos iniciais do ensino fundamental ganhou destaque nas avaliações nacionais em larga escala, tanto no âmbito federal quanto no estadual, em consequência do nível de aprendizado insatisfatório da maioria dos alunos do $5^{\circ}$ ano do ensino fundamental, que está relacionado à aprendizagem insuficiente dos alunos nos anos anteriores a essa etapa escolar.

Assim, a partir da compreensão de que os resultados insatisfatórios dos alunos são decorrentes de uma defasagem acumulada de conhecimentos e habilidades desde o início da alfabetização, surgiram não apenas as avaliações em larga escala para os anos iniciais do ensino fundamental, mas também outras iniciativas como a ampliação da duração desse nível de escolarização para nove anos. Esta implicou o 
ingresso dos alunos na escola aos seis anos de idade e a ênfase na alfabetização ao longo dos três primeiros anos escolares (Lei n. 11.274/2006).

Além disso, foi criado o Pacto Nacional pela Alfabetização na Idade Certa (Pnaic), um compromisso formal assumido pelos municípios, estados, distrito federal e governo federal para a garantia da alfabetização de todas as crianças até os oito anos de idade, quando estas deveriam concluir o $3^{\circ}$ ano do ensino fundamental.

\section{ANÁLISE DOS DADOS}

Os estudos estatísticos sobre a desigualdade educacional no Brasil, segundo Alves e Franco (2008, p. 493), têm sido realizados com o objetivo de investigar as diferenças de desempenho dos alunos do ponto de vista interno às escolas. Por exemplo, Franco et al. (2002, p. 21), analisando dados do Sistema Brasileiro de Avaliação da Educação Básica (Saeb), verificaram que, mesmo após a introdução do controle dos resultados educacionais pelo índice socioeconômico (ISE) médio das escolas, ainda persiste uma associação significativa entre o índice socioeconômico individual dos alunos e seus respectivos resultados de proficiência, muito embora tal associação também varie entre as escolas. Esse último ponto é relevante, porque permite constatar que as escolas em geral podem variar não apenas quanto a seus resultados médios de proficiência, mas também quanto à maior ou menor equanimidade com que ensinam seus alunos.

Nessa mesma linha, Soares e Andrade (2006, p. 126), em um estudo sobre escolas na capital de Minas Gerais, atestaram que "o sistema de educação básica de Belo Horizonte só consegue produzir qualidade na presença de alta iniquidade". Isso porque as escolas com os maiores resultados médios nas avaliações utilizadas no estudo foram também aquelas que, em geral, apresentaram as maiores variações internas de resultados. As variações de desempenho, além de estarem associadas a diferenças socioeconômicas dos alunos, também podem estar relacionadas a desigualdades raciais, conforme demonstraram Soares e Alves (2003, p. 159) que, 
em estudo com dados do Saeb, verificaram a existência de um grande hiato entre alunos brancos e negros e, em menor grau, entre alunos brancos e pardos em relação ao desempenho escolar. Constataram, ainda, que os fatores produtores de eficácia do ensino não se distribuem de forma equânime, favorecendo principalmente o desempenho escolar dos alunos brancos e contribuindo para acirrar, e não para reduzir, a diferença entre os grupos raciais.

No presente estudo, é possível observar alguns pontos de interseção com as referências supracitadas. Pretende-se analisar eventuais desigualdades de conhecimento dos alunos dentro das escolas, com base nos resultados das avaliações em larga escala, levando em conta a influência de determinadas características dos alunos, tais como condição socioeconômica, cor/raça e sexo.

Tendo em vista o propósito de investigar a desigualdade de conhecimento num contexto escolar público brasileiro, optou-se por trabalhar com os resultados dos testes de Leitura de uma avaliação em larga escala - o Paebes-Alfa -, adotando-se, para isso, uma abordagem estatística que permite verificar se o conhecimento adquirido pelos estudantes é satisfatório e se sua distribuição é mais ou menos igualitária. O Quadro 1 apresenta o número total de estudantes matriculados no sistema educacional do Espírito Santo em cada um dos três primeiros anos do ensino fundamental, seguido do número total de alunos que realizaram os testes cognitivos e do número de alunos considerados nesta análise.

QUADRO 1 - Número de alunos matriculados no ensino fundamental no estado do Espírito Santo, número de participantes do Paebes-Alfa e dos alunos considerados para a análise dos dados

\begin{tabular}{|c|c|c|c|c|}
\hline \multirow{2}{*}{$\begin{array}{c}\text { ANO DA } \\
\text { AVALIAÇÃO }\end{array}$} & \multirow{2}{*}{ ANO DO EF } & \multicolumn{3}{|c|}{ NÚMERO DE ALUNOS } \\
\cline { 3 - 4 } & & MATRICULADOS* & $\begin{array}{c}\text { PARTICIPANTES } \\
\text { PAEBES-ALFA** }\end{array}$ & $\begin{array}{c}\text { CONSIDERADOS } \\
\text { PARA A ANÁLISE** }\end{array}$ \\
\hline 2012 & $1^{\circ}$ & 54.271 & 34.778 & \multirow{2}{*}{7.781} \\
\hline 2013 & $2^{\circ}$ & 55.872 & 36.316 & \\
\hline 2014 & $3^{\circ}$ & 63.068 & 39.277 & \\
\hline
\end{tabular}

Fonte: $\left(^{*}\right)$ site QEDU. Endereço eletrônico: <http://www.qedu.org.br/>; $\left.{ }^{* *}\right)$ Dados do Paebes-Alfa. 
Por tratar-se de uma pesquisa que utiliza dados de uma avaliação longitudinal com o objetivo de investigar a desigualdade de conhecimento, alguns critérios de seleção dos alunos e das escolas foram estabelecidos. O primeiro critério diz respeito à seleção de estudantes das escolas públicas, excluindo-se, assim, aqueles pertencentes às escolas particulares participantes. $\mathrm{O}$ segundo critério considerou escolas com duas turmas ou mais, excluindo-se, portanto, escolas com menos de duas turmas. Por fim, para preservar a natureza longitudinal dos dados, foram considerados os estudantes que possuíam informações de proficiência nas quatro ondas de avaliação, a saber: avaliação de entrada no $1^{\circ}$ ano, em 2012; avaliação de saída no $1^{\circ}$ ano, em 2012; avaliação de saída no $2^{\circ}$ ano, em 2013; e avaliação de saída no $3^{\circ}$ ano, em 2014. Assim, após a filtragem dos casos de acordo com os critérios adotados, o número total considerado para a análise foi de 7.781 estudantes, distribuídos em turmas de alto e baixo desempenho, de escolas públicas urbanas e rurais, seguindo procedimentos que serão apresentados mais à frente.

O estudo também optou por trabalhar com uma modelagem linear hierárquica, pois os resultados educacionais, em regra, revestem-se de uma natureza pela qual os alunos se agrupam em turmas, e estas em escolas, de modo que turmas e escolas podem variar significativamente entre si quanto a diversas variáveis de interesse, como o índice socioeconômico médio de seus integrantes, variáveis específicas dos professores e as atitudes médias dos alunos em relação ao ensino ou à aprendizagem (RAUDENBUSH; BRYK, 2002).

No presente caso, analisaram-se os percentuais de acerto dos itens nos testes, bem como sua variação. Dessa maneira, se o item tiver um alto percentual de acerto, isso indica que a habilidade de Leitura avaliada pelo item foi adquirida e consolidada pela maioria dos alunos. Por outro lado, se o item tiver um baixo percentual de acerto, isso indica que poucos alunos adquiriram a habilidade avaliada. Se a variação desse percentual entre as turmas for alta, significa que, no interior da escola, a aquisição da habilidade foi desigual. Se a variação for pequena, o aprendizado da habilidade na escola foi mais homogêneo ou mais igualitário. 
Quando se analisam os percentuais de acerto dos itens de uma avaliação educacional, um problema que se coloca é a instabilidade das médias, uma vez que elas dependem diretamente da proficiência dos alunos (HOGAN, 2006). Dessa forma, há uma ampla gama de situações possíveis, estendendo-se entre dois limites: um superior, no qual os itens apresentam médias de acerto próximas a $100 \%$, revelando a existência de um estado de consolidação da aprendizagem em aproximadamente todos os estudantes avaliados, e um inferior, no qual os itens possuem médias de acerto nulas ou quase nulas (especialmente quando corrigidos para o acerto casual). Nessa última situação, os resultados sugerem que a habilidade mensurada no item pode ter sido tratada pelo professor de forma inadequada ou, ainda, pode nem ter sido trabalhada com os estudantes em sala de aula.

No presente estudo, as médias de desempenho em cada item foram estimadas a partir dos dados das respostas dos alunos, variáveis que tinham uma codificação binária, onde o valor nulo corresponde ao erro e o valor unitário, ao acerto. Além disso, e como já observado, levou-se em conta, na análise, a natureza hierárquica dos dados, visto que, nesse caso, desejava-se estudar o desempenho dos alunos agrupados em turmas e escolas. Outro ponto de interesse foi incorporar, na estimação dos percentuais de acerto, os efeitos de algumas variáveis do nível do aluno que, conforme amiúde demonstrado na literatura, encontram-se associadas de forma significativa ao desempenho escolar, tais como o nível ou índice socioeconômico do aluno ou de sua família (XAVIER; ALVES, 2015), sua cor/raça (SOARES; ALVES, 2003) e gênero (CARVALHO, 2003).

O Quadro 2 apresenta as estatísticas descritivas referentes aos 7.781 alunos que compuseram a presente amostra e que foram avaliados inicialmente no $1^{\circ}$ ano do ensino fundamental na rede pública do Espírito Santo, em 2012. 
QUADRO 2 - Estatísticas descritivas da amostra de alunos do $1^{\circ}$ ano $\mathrm{EF}^{2}$

\begin{tabular}{|c|c|c|c|}
\hline & $\begin{array}{c}\text { ÍNDICE SOCIO- } \\
\text { ECONÔMICO } \\
\text { (ISE) }\end{array}$ & $\begin{array}{c}\text { RAÇA } \\
\text { (BRANCO) }\end{array}$ & $\begin{array}{c}\text { SEXO } \\
\text { (FEMININO) }\end{array}$ \\
\hline Média & 0,19 & 0,34 & 0,53 \\
\hline Desvio-padrão & 0,93 & 0,47 & 0,50 \\
\hline
\end{tabular}

Fonte: Dados do Paebes-Alfa (elaboração própria).

Por esse quadro, observa-se que o índice socioeconômico, na escala para ele criada, possui valores próximos de zero $(0,19)$ e de uma unidade $(0,93)$, respectivamente para a média e o desvio-padrão. Quanto à cor da pele e o sexo, expressos em proporção, constata-se que cerca de um terço (34\%) dos alunos é branco e que pouco mais da metade (53\%) é do sexo feminino.

Com base nessas variáveis, obteve-se a formulação de um modelo linear hierárquico de três níveis, no qual o primeiro deles é o do aluno, o segundo é o da turma e o terceiro, o da escola, conforme se vê nas seguintes equações:

Nível 1 (aluno):

$$
\operatorname{LOG}(\mathrm{AC})_{i j k}=\pi_{0 j k}+\pi_{l j k}(\mathrm{ISE})+\pi_{2 j k}(\mathrm{BRANCO})+\pi_{3 j k}(\mathrm{FEM})+e_{i j}
$$

onde as variáveis são:

LOG(AC): logaritmo natural da chance de acerto $P$ que um aluno $i$, estudando na turma $j$ da escola $k$, possui em relação a um determinado item.

ISE: índice socioeconômico do aluno, ${ }^{3}$ centralizado na grande média, do mesmo modo que as duas variáveis explicativas seguintes.

BRANCO: cor do aluno ( 0 = não branco, 1 = branco).

FEM: gênero do aluno ( 0 = masculino, 1 = feminino).

E os coeficientes são:

$\pi_{0 j k}$ : percentual médio do logaritmo da chance de acerto dos alunos da turma $j$ da escola $k$ quanto a determinado item, controlando-se pelo seu respectivo índice socioeconômico, cor e gênero.

$\pi_{1 j k}, \pi_{2 j k}, \pi_{3 j k}$ : correspondem respectivamente aos coeficientes de regressão para o índice socioeconômico, a cor e o gênero dos alunos da turma $j$ da escola $k$.

$e_{i j}$ : erro estocástico da medida do aluno.
2 A forma de obtenção do índice socioeconômico é discutida na nota 3, a seguir. Quanto à raça (branca) e ao sexo (feminino) dos alunos, trata-se de variáveis binárias, valendo respectivamente 1 para brancos ou meninas, e $\mathrm{O}$ para não brancos ou meninos. A média dessas variáveis binárias é igual a $P$, dada pela expressão $(\Sigma X) / N$, onde $X$ corresponde ao valor individual da variável e $N$, ao total de casos. Por sua vez, o desvio-padrão $D P$ é obtido pela expressão $\left.D P=\sqrt{(} P^{*}(1-P) / N\right)$.
3 O índice socioeconômico foi calculado com base na Teoria da Resposta ao Item (TRI), mediante a utilização do software Bilog MG, segundo Mislevy e Bock (1990), e fol construído com base nos itens do questionário contextual aplicado aos pais/responsáveis dos alunos dos 1 (2012), 2 (2013) e 3 (2014) anos do ensino fundamental. Os itens que compõem o índice são: escolaridade dos pais, situação de trabalho, quantidade de livros (não escolares) em casa, frequência com que realiza leituras e acesso a bens e serviços (rua asfaltada, energia elétrica, água na torneira, coleta de lixo, benefício do Bolsa Família, empregada doméstica/faxineira, banheiro em casa, rádio, TV em cores, geladeira, máquina de lavar roupa, aparelho de DVD, automóvel (carro/moto), computador, dicionário de Língua Portuguesa/outras línguas). Por sua vez, essas medidas foram obtidas pelo Centro de Políticas Públicas e Avaliação da Educação (CAEd) na Universidade Federal de Juiz de Fora (UFJF), em parceria com a Secretaria de Educação do Espírito Santo. Informações mais detalhadas sobre o ISE podem ser obtidas nos questionários contextuais publicados por essa Secretaria, como em Espírito Santo (2013). 
Já no nível 2 (da turma), as equações para as turmas de uma escola $k$ ficam do seguinte modo:

$\pi_{n j k}=\beta_{n o k}+r_{n j k} \quad$ onde $n \varepsilon\{0,1,2,3\}$ e:

$\beta_{n o k}$ : média da turma $j$ da escola $k$, correspondente ao percentual médio de acerto esperado de um determinado item. $r_{n j k}$ : erro estocástico da média da turma.

E, no nível 3 (escola), tem-se:

$\beta_{n k}=\gamma_{n 0}+u_{n k} \quad$ onde $n \varepsilon\{0,1,2,3\}$ e:

$\gamma_{n 0}$ : média da escola $k$, correspondente ao percentual médio de acerto esperado de um determinado item.

$u_{n k}:$ erro estocástico da média da escola.

Percebe-se portanto que, no nível do aluno, há três variáveis explicativas - índice socioeconômico, cor da pele e gênero -, ao passo que, no nível da turma e da escola, o modelo é incondicional. E, em todos os três níveis, há um termo residual, ou estocástico, que indica a diferença entre o seu valor observado e o seu respectivo valor previsto. Dessa forma, valores positivos desses resíduos indicam que o sujeito em análise possui um desempenho observado superior ao previsto, e valores negativos indicam o contrário. Portanto, somando algebricamente os resíduos dos alunos no nível das turmas às quais estes pertencem (ponderando-se pelo seu número de estudantes), é possível diferenciar as turmas dentro de uma mesma escola quanto ao seu desempenho médio não explicado pelo modelo. E algo análogo é obtido quando se agregam as médias das turmas (ponderando-se pelos seus respectivos tamanhos) para o nível das suas escolas.

O Quadro 3 resume algumas estatísticas relevantes desse modelo:

QUADRO 3 - Coeficientes de fidedignidade e percentuais de variância para as chances de acerto dos itens, por nível de análise no modelo linear hierárquico adotado

\begin{tabular}{|c|c|c|c|c|c|}
\hline & \multicolumn{2}{|c|}{$\begin{array}{c}\text { COEFICIENTE DE } \\
\text { FIDEDIGNIDADE }\end{array}$} & \multicolumn{3}{c|}{ \% DA VARIÂNCIA } \\
\hline & TURMA & ESCOLA & ALUNO & TURMA & ESCOLA \\
\hline Média & 0,413 & 0,317 & 37,5 & 36,9 & 25,7 \\
\hline Desvio-padrão & 0,181 & 0,100 & 14,6 & 15,0 & 9,1 \\
\hline
\end{tabular}

Fonte: Dados do Paebes-Alfa (elaboração própria). 
É possível observar, pelo quadro, que os coeficientes de fidedignidade no nível da turma e no da escola - cujas médias se situam respectivamente na casa de 0,4 e 0,3 - são elevados o suficiente para se concluir que, em geral, as médias de desempenho, tanto das turmas dentro de uma mesma escola como das escolas entre si, variam consideravelmente, o que justifica a adoção de tal modelo de três níveis. Essa observação é também corroborada, como visto no quadro, pela análise dos percentuais de variância associados às turmas (que corresponde a mais de um terço da variância total dos resultados observados) e às escolas (correspondente a cerca de um quarto dessa variância total).

Após a utilização desse modelo, que fornece o logaritmo da chance de acerto, é possível chegar ao percentual previsto deste último, $p$, a partir da equação do nível do aluno já mencionada (e onde as variáveis de controle são todas nulas), da seguinte forma:

$$
A C=p /(1-p)=\operatorname{EXP}\left[\pi_{0 j k}\right]
$$

Ou, resolvendo-se para a probabilidade $p$ de acerto:

$$
p=A C /(1+A C)=\operatorname{EXP}\left[\pi_{0 j k}\right] /\left(1+\operatorname{EXP}\left[\pi_{0 j k}\right]\right)
$$

Dessa maneira, foi possível estimar os percentuais de acerto de cada item do Paebes-Alfa, controlados pelas três variáveis já citadas no nível do aluno. Porém, antes de analisar esses percentuais, optou-se por levar em conta também o acerto casual dos itens. No teste de Leitura, todos os itens eram de múltipla escolha e continham quatro opções de resposta. Com essa configuração, a probabilidade de acerto é significativa, mesmo que o respondente não tenha os conhecimentos necessários para acertar o item. A fim de atenuar esse problema na interpretação das médias dos percentuais de acerto, utilizou-se um procedimento para a correção do acerto casual, dado pela seguinte fórmula:

$$
\text { Perc_corrigido }=\text { Perc_real }-(100-\text { Perc_real }) /(N-1)
$$

onde:

Perc_corrigido: percentual esperado corrigido do item para o acerto casual. 
4 A correlação de Pearson é calculada por meio da raiz quadrada
Perc_real: percentual esperado bruto de acerto do item. $\mathrm{N}$ : número de opções da múltipla escolha para o item específico (no Paebes-Alfa, as opções de resposta de cada item de Leitura são sempre quatro).

No total, foram analisadas 349 escolas e 1.168 turmas. Nessa análise, os resultados individuais dos alunos foram agregados por suas respectivas turmas e, numa segunda etapa, também por suas escolas. Desse modo, as medidas mostradas nos gráficos 1 e 2 , a seguir, correspondem às médias e aos desvios padrão dos percentuais médios e previstos de acerto na totalidade dos itens apresentados na prova, e agregados inicialmente para as diferentes turmas dentro de uma mesma escola, ponderando-se pelas respectivas quantidades de alunos avaliados.

Tal abordagem permitiu analisar a associação entre as médias dos percentuais de acerto dos itens que cada escola respondeu e os seus respectivos desvios padrão, como se observa nos gráficos.

Por exemplo, conforme mostra o Gráfico 1 , no $1^{\circ}$ ano, em 2012, a associação dessas duas medidas é muito fraca, correspondendo a uma correlação de Pearson igual a 0,084. ${ }^{4}$ Embora esse valor seja muito próximo de zero, a inclinação da reta parece indicar uma sutil relação entre as médias e os desvios padrão do número de acertos dos itens. Ou seja, escolas cujas turmas obtêm, em média, maiores resultados tendem a ser aquelas em que se observa uma maior variabilidade entre as turmas. Já no $3^{\circ}$ ano, em 2014, o Gráfico 2 mostra que a correlação entre essas duas medidas é de -0,53, o que implica o contrário do que se observou na (embora tênue) associação do $1^{\circ}$ ano. Tem-se, agora, um novo padrão pelo qual, quanto maiores as médias dos percentuais de acerto nas turmas das escolas, maior também a homogeneidade de seus respectivos resultados, ou seja, menores os seus desvios padrão.

Isso possivelmente significa que, ao longo do ciclo de alfabetização, as escolas que mais agregaram valor quanto à variável de proficiência aqui utilizada (as chances de acerto em Língua Portuguesa) podem ter passado por alguns processos de reorganização que tornaram seus respectivos resultados de proficiência mais homogêneos ou equitativos. E tal associação, inexistente no $1^{\circ}$ ano, passou a ser observada no $3^{\circ}$ ano. 
GRÁFICO 1 - Associação entre a média (eixo horizontal) e o desvio-padrão (vertical) dos percentuais de acerto dos itens entre as turmas dentro de uma mesma escola, no $1^{\circ}$ ano do ensino fundamental

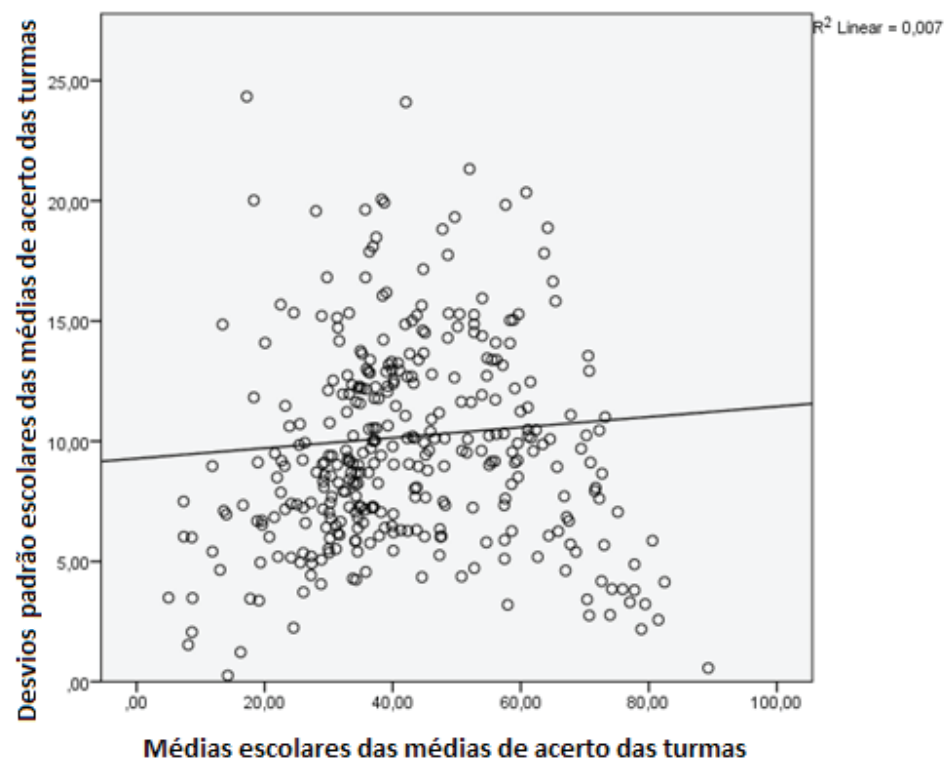

Fonte: Dados do Paebes-Alfa (elaboração própria).

GRÁFICO 2 - Associação entre a média (eixo horizontal) e o desvio-padrão (vertical) dos percentuais de acerto dos itens entre as turmas dentro de uma mesma escola, no $3^{\circ}$ ano do ensino fundamental

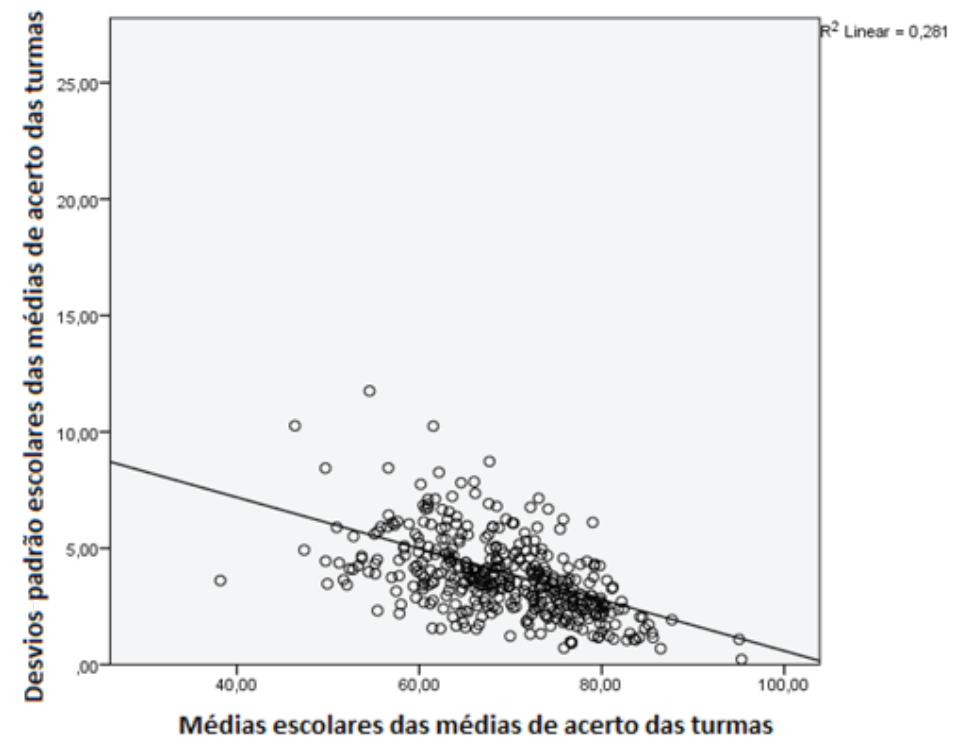

Fonte: Dados do Paebes-Alfa (elaboração própria). 
Ao mesmo tempo, ao levar em conta especificamente nesta análise o grau de complexidade das habilidades de Leitura avaliadas no $3^{\circ}$ ano, também se observa que as médias dos percentuais de acerto das turmas dentro das escolas tendem a ser relativamente maiores, ao passo que seus respectivos desvios padrão tendem a ser menores do que no $1^{\circ}$ ano. Em outras palavras, poucos alunos adquirem aprendizagens complexas, e essa aquisição se dá de forma desigual no interior da escola.

A partir desses resultados mais gerais, buscou-se averiguar como as habilidades mais complexas se encontram associadas às características sociais clássicas - nível socioeconômico, cor/raça e sexo dos alunos. Com esse propósito, primeiramente se procedeu a uma classificação dos itens baseada na norma, fornecida pelo valor de seu respectivo parâmetro de dificuldade $B$, da TRI, expresso na escala de proficiência do teste em questão.

De acordo com Hambleton et al. (1991), por meio da TRI, é possível, para cada item do teste, construir uma função que relaciona a proficiência estimada de um indivíduo e a chance de ele acertar um dado item do teste, segundo uma escala logarítmica. Dessa forma, cada item possui a sua curva característica, por esse motivo chamada de Curva Característica do Item (CCI).

$\mathrm{Na} \mathrm{CCI}$, as curvas dos itens apresentam, grosso modo, a forma de um "S" alongado, estendendo-se lateralmente segundo duas assíntotas horizontais: uma inferior e igual ou maior que zero na extremidade esquerda do gráfico (e inferior das proficiências), e outra superior e igual a um na extremidade direita do gráfico (e superior das proficiências), indicando que, nesse último caso, a possibilidade de ocorrência de um acerto do item se aproxima de $100 \%$ dos casos. Ainda em relação às CCIs, quanto mais elas se deslocam para a direita (ou seja, na direção dos maiores níveis de proficiência), mais difíceis se consideram os seus respectivos itens. E o parâmetro B de dificuldade se relaciona, precisamente, a esse deslocamento lateral da curva no gráfico do item, associado à sua respectiva dificuldade. Também cabe mencionar que os parâmetros B, assim como várias outras medidas da 
TRI, após serem obtidos originalmente numa escala padronizada, em geral, sofrem transformações lineares que não alteram a essência de sua informação, mas, ao mesmo tempo, têm a vantagem de expressá-los em escalas mais adequadas para a sua compreensão ou interpretação, em especial para um público tecnicamente não especializado na obtenção de tais medidas.

Desse modo, a escala da medida de dificuldade dos itens foi dividida em quatro partes (quartis), de forma a classificar os itens com grau de dificuldade alto ( $4^{\circ}$ quartil), médio $\left(3^{\circ} \mathrm{e}\right.$ $2^{\circ}$ quartis) e baixo ( $1^{\circ}$ quartil). Os itens considerados difíceis no $1^{\circ}$ ano apresentaram o parâmetro B superior a 529,7 na escala de proficiência, e os itens considerados difíceis no $3^{\circ}$ ano obtiveram parâmetro B superior a 715,1.

Para os itens difíceis, tanto do $1^{\circ}$ quanto do $3^{\circ}$ ano, os resultados mostraram que, na maioria dos casos, não houve efeito estatisticamente significativo das variáveis sociais sobre o percentual de acerto dos itens. ${ }^{5} \mathrm{E}$, nos casos em que esses efeitos foram significativos, eles atuaram no mesmo sentido observado pelas referências já mencionadas, ou seja, associando-se positivamente ao aumento do índice socioeconômico e à ocorrência de alunos brancos e do sexo feminino.

Dessa forma, e em face de tais resultados, complementou-se a análise anterior utilizando o percentual de acerto dos itens difíceis e sua variação segundo o nível de desempenho das turmas, considerando as habilidades avaliadas por esses itens. Implementou-se o controle do efeito da composição social da escola, e basearam-se as comparações do percentual de acerto de itens difíceis nos testes de Leitura de acordo com o parâmetro B, de modo a aumentar as chances de as diferenças entre os dois grupos de turmas refletirem o currículo efetivamente ensinado e suas semelhanças e diferenças de ênfase, quer se trate de um ou de outro grupo de turmas.

Por um lado, considerou-se na análise que o alto percentual de acerto de um item mostra que a habilidade avaliada foi dominada por praticamente todos os estudantes, e que esse resultado evidenciaria a eficácia do trabalho da escola em garantir o aprendizado daquele conteúdo. Por outro
5 Entre os itens analisados e num nível de significância de $95 \%$ ou mais, não houve resultados significativos em 21 itens quanto ao índice socioeconômico dos alunos, em 29 itens quanto à cor da pele e em 30 itens quanto ao gênero dos alunos. 
6 Disponivel em: <http://www paebesalfa2onda.caedufjf.net/ avaliacao-educacional/matriz-dereferencia/>. Acesso em: 10 maio 2016 lado, foi considerado, também, que um item com baixo percentual de acerto indicaria que poucos alunos adquiriram a habilidade avaliada e que, portanto, a escola possivelmente teria trabalhado de forma inadequada aquele conteúdo. Por sua vez, em termos da categoria igualdade de conhecimento, que baliza este estudo, itens com alta variação do percentual de acerto entre as turmas evidenciariam que a habilidade avaliada foi trabalhada de forma diferenciada entre os dois agrupamentos, inclusive entre os itens que apresentam alta variação do percentual de acerto, mas para os quais a média desse percentual é baixa para as turmas de baixo e de alto desempenho.

Além disso, o estudo identificou as diferenças na evolução geral de aprendizagem entre os dois grupos de turmas e a composição dessas diferenças em termos de conteúdo curricular de Leitura.

Nesse processo de análise, levou-se em conta a matriz de referência em Língua Portuguesa do Paebes-Alfa, ${ }^{6}$ que é composta por cinco tópicos. Em cada tópico, são apresentadas as competências, as habilidades, os níveis de complexidade das habilidades e os anos em que cada habilidade é avaliada. Embora a matriz do Paebes-Alfa, como toda matriz de referência, represente apenas um recorte do currículo, relacionado ao que pode ser aferido por meio de testes padronizados tipicamente utilizados na avaliação em larga escala, ela apresenta importantes elementos associados a habilidades e competências a serem desenvolvidas na etapa da alfabetização. Isso permite a análise do percentual de acerto dos itens em cada ano e, portanto, pode fornecer pistas acerca da ênfase dada a diferentes dimensões do conteúdo curricular no processo de ensino e de aprendizagem relativo ao ciclo de alfabetização.

\section{$1^{\circ}$ ANO DO ENSINO FUNDAMENTAL}

A partir deste ponto, serão apresentados os percentuais de acerto dos itens difíceis e sua variação segundo o nível de desempenho das turmas, além das habilidades avaliadas.

O procedimento adotado para observar a igualdade de conhecimento (CRAHAY, 2002) entre as turmas foi o de dividir 
o desempenho obtido por elas em alto, médio e baixo. Para realizar essa classificação, os dados de proficiência foram divididos em tercis, de forma que o tercil mais baixo se refere às turmas de baixa proficiência, o tercil do meio, às turmas de média proficiência e o tercil mais alto às turmas de alta proficiência. Neste estudo, foram analisados os dados das turmas de alta e baixa proficiência, de modo a observar se as habilidades complexas são adquiridas de forma homogênea ou heterogênea entre os dois agrupamentos de turmas.

O Quadro 4 apresenta o percentual de acerto, a diferença do percentual de acerto entre as turmas de alto e baixo desempenho e a habilidade avaliada pelo item. As linhas do quadro estão ordenadas de forma decrescente, segundo a coluna que indica a diferença do percentual de acerto entre os dois agrupamentos.

QUADRO 4 - Percentual de acerto dos itens difíceis e sua variação segundo o nível de desempenho do grupo $-1^{\circ}$ ano do ensino fundamental

\begin{tabular}{|c|c|c|c|c|}
\hline \multirow[t]{2}{*}{ ITEM } & \multirow[t]{2}{*}{ HABILIDADE } & \multicolumn{2}{|c|}{$\begin{array}{l}\text { NÍVEL DE DESEMPENHO } \\
\text { DO GRUPO }\end{array}$} & \multirow{2}{*}{$\begin{array}{l}\text { DIFERENCCA } \\
\text { ENTRE OS } \\
\text { GRUPOS }\end{array}$} \\
\hline & & BAIXO & ALTO & \\
\hline P42 & Identificar o número de sílabas de uma palavra (consciência silábica). & 18,1 & 64,6 & 46,5 \\
\hline P72 & Reconhecer a finalidade de gêneros diversos. & 3,1 & 44,0 & 40,9 \\
\hline P66 & Distinguir, como leitor, diferentes tipos de letras. & 2,6 & 41,8 & 39,2 \\
\hline P61 & $\begin{array}{l}\text { Ler frases e pequenos textos, localizando informações explícitas } \\
\text { contidas neles. }\end{array}$ & 3,4 & 42,6 & 39,2 \\
\hline P67 & Identificar o número de sílabas de uma palavra (consciência silábica). & 13,8 & 48,7 & 34,9 \\
\hline P63 & $\begin{array}{l}\text { Reconhecer o local de inserção de determinada palavra numa } \\
\text { sequência em ordem alfabética. }\end{array}$ & 23,2 & 57,3 & 34,1 \\
\hline P68 & $\begin{array}{l}\text { Ler frases e pequenos textos, localizando informações explícitas } \\
\text { contidas neles. }\end{array}$ & 0,0 & 33,2 & 33,2 \\
\hline $\mathrm{P} 80$ & Identificar assunto de textos. & 25,0 & 57,7 & 32,7 \\
\hline P64 & $\begin{array}{l}\text { Localizar informações explícitas em textos de maior extensão ou em } \\
\text { textos que apresentam dados. }\end{array}$ & 8,5 & 40,9 & 32,3 \\
\hline P75 & Identificar assunto de textos. & 1,1 & 32,8 & 31,6 \\
\hline P34 & Identificar elementos que constroem a narrativa. & 30,2 & 60,9 & 30,7 \\
\hline P58 & $\begin{array}{l}\text { Localizar informações explícitas em textos de maior extensão ou em } \\
\text { textos que apresentam dados. }\end{array}$ & 31,8 & 62,2 & 30,4 \\
\hline P71 & $\begin{array}{l}\text { Reconhecer o local de inserção de determinada palavra numa } \\
\text { sequência em ordem alfabética. }\end{array}$ & 0,9 & 26,7 & 25,9 \\
\hline P57 & Identificar gêneros textuais diversos. & 31,4 & 56,3 & 24,9 \\
\hline P69 & Reconhecer a finalidade de gêneros diversos. & 2,1 & 26,3 & 24,2 \\
\hline P73 & Identificar elementos que constroem a narrativa. & 1,2 & 25,1 & 23,9 \\
\hline P62 & $\begin{array}{l}\text { Reconhecer o local de inserção de determinada palavra numa } \\
\text { sequência em ordem alfabética. }\end{array}$ & 4,0 & 27,0 & 23,1 \\
\hline P14 & $\begin{array}{l}\text { Identificar silabas e sons (consciência silábica e consciência } \\
\text { fonêmica). }\end{array}$ & 75,7 & 81,9 & 6,2 \\
\hline
\end{tabular}

Fonte: Dados do Paebes-Alfa (elaboração própria). 
Em geral, pode-se dizer que os itens avaliados no $1^{\circ}$ ano foram difíceis para as turmas de baixo desempenho e médios para as de alto desempenho. Isso pode ser percebido nas diferenças dos valores do percentual de acerto entre esses dois grupos, que variam, na maioria dos casos, entre $47 \%$ e $25 \%$. Somente no caso do item P14, que avalia a habilidade relacionada à consciência silábica e fonêmica, a diferença dos percentuais de acerto dos dois grupos de turmas decresce consideravelmente, para ficar na casa dos $6 \%$.

Uma ressalva importante sobre essas diferenças é que os itens mostrados no Quadro 4 fizeram parte da avaliação dos alunos no início do $1^{\circ}$ ano. Isso significa que os resultados apresentados ainda não conseguem refletir o trabalho das escolas e dos professores. O mais provável é que esses resultados sejam produto do background familiar e/ou da frequência prévia desses alunos à educação infantil. De qualquer forma, o percentual de acerto dos itens no $1^{\circ}$ ano foi incluído nesta pesquisa por ser considerado útil para o estudo tanto da aprendizagem agregada pela escola como da evolução da variação dessas aprendizagens das turmas entre o início do $1^{\circ}$ e o fim do $3^{\circ}$ ano.

Como pode ser observado ainda no Quadro 4, nos dois itens que avaliam a habilidade de ler frases e pequenos textos localizando informações explícitas (P68 e P61), o percentual de acerto entre as turmas com baixo desempenho é nulo ou não ultrapassa $3,4 \%$, revelando que os alunos não possuem a habilidade avaliada. Nas turmas de alto desempenho, os percentuais de acerto desses dois itens foram, respectivamente, $33,2 \%$ e $42,6 \%$, o que indica que cerca de um terço ou um pouco mais dos alunos dessas turmas já apresentava essa habilidade ao iniciar o $1^{\circ}$ ano escolar. Também pode ser observado, entre as turmas de baixo desempenho, que nos itens P75 (identificar assunto de textos), P71, P62 (reconhecer o local de inserção de determinada palavra numa sequência em ordem alfabética), P73 (identificar elementos que constroem a narrativa) e P69 (reconhecer a finalidade de gêneros diversos), o percentual de acerto mal se aproxima de $3 \%$, indicando que os alunos dessas turmas não possuem as habilidades avaliadas. Já entre os alunos das turmas de alto desempenho, o 
percentual de acerto desses mesmos itens oscila entre $25 \% \mathrm{e}$ $32 \%$. No entanto, é na habilidade de identificar o número de sílabas de uma palavra, avaliada pelos itens P42 e P67, que a variação do percentual de acerto entre as turmas está entre as mais altas (46,5\% e $34,9 \%$, respectivamente), confirmando a desigualdade de conhecimento presente no âmbito intraescolar no $1^{\circ}$ ano.

Esses itens estão ancorados no padrão de desempenho avançado e a correlação bisserial item-teste ${ }^{7}$ é de 0,465 (item P42) e 0,446 (P67), o que indica que eles discriminam bem os alunos que dominam a habilidade daqueles que ainda não a dominam, confirmam o bom ajuste do item ao teste e informam que os alunos que mais acertaram no teste também acertaram esses itens. Ou seja, são itens que avaliam bem a habilidade que se propõem a avaliar.

Em síntese, as habilidades de reconhecer a finalidade de gêneros diversos; distinguir, como leitor, diferentes tipos de letras; ler frases e pequenos textos, localizando informações explícitas; identificar o número de sílabas de uma palavra (consciência silábica); e reconhecer o local de inserção de determinada palavra numa sequência em ordem alfabética se configuram como aquelas que apresentam maior desigualdade entre as turmas do $1^{\circ}$ ano do ensino fundamental.

O item P64 (localizar informações explícitas em textos de maior extensão ou em textos que apresentam dados), utilizado na avaliação de entrada no $1^{\circ}$ ano (2012), foi o único divulgado pelo Paebes-Alfa, o que viabilizou sua interpretação pedagógica. O item está ancorado no padrão de desempenho avançado e a correlação bisserial é alta, de 0,524, indicando que esse item discrimina bem os alunos que dominam a habilidade daqueles que não a dominam e que o ajuste do item ao teste é bom. Além disso, indica que os alunos que se saíram melhor no teste também acertaram esse item. A Figura 1 apresenta o item.
7 A correlação bisserial é considerada boa a partir do valor 0,30. Itens que possuem uma correlação bisserial abaixo de 0,30 convencionalmente são aqueles que não discriminam bem os alunos que dominam a habilidade avaliada daqueles que não a dominam. 
O ELEFANTINHO ESTAVA COM MEDO PORQUE

ANDAVA DESCONSOLADO

ENCONTROU UM PASSARINHO

$\square$ ESPETOU O PÉ NO ESPINHO.

Conforme pode ser observado, esse item exige a identificação de uma informação explícita sobre o encontro do protagonista com outro personagem, em um poema infantil, gênero textual comumente abordado nos anos iniciais do ensino fundamental. Alunos que têm experiência na escola com a leitura de poemas reconhecem a estrutura organizacional desse gênero e fatos ficcionais que transcorrem com os personagens. Para realizar a tarefa proposta com êxito, o estudante deve inferir a causa de um evento que, no caso, é o medo do passarinho. A habilidade avaliada diz respeito à evolução dos eventos, que leva em conta a relação de causa e consequência, ou seja, qual fato dá origem a outro fato. No caso, é o medo do passarinho que faz com que o elefantinho tenha um passo apressado, um andar perdido e um ar desconsolado. O conectivo, marca linguística de uma relação de causa, não está sinalizado no poema, o que exige do aluno a habilidade de fazer inferências. Entretanto, o conectivo porque está presente no comando, o que torna mais clara a relação de causa e consequência. 
O item apresenta baixo índice de acerto no grupo de baixo desempenho, de $8,5 \%$, sugerindo que a grande maioria dos participantes do teste que se encontra nessas turmas não domina a habilidade avaliada. Entre as turmas com maior desempenho, esse percentual foi de $40,9 \%$. Esse resultado indica que, provavelmente, no grupo das turmas de alto desempenho, apesar da diferença de $32,3 \%$ com relação às de baixo desempenho, a maioria dos alunos também não domina a habilidade avaliada em sua completude.

\section{$3^{\circ}$ ANO DO ENSINO FUNDAMENTAL}

O Quadro 5 apresenta os mesmos dados para o $3^{\circ}$ ano do ensino fundamental. Nesse ano escolar, os resultados dos alunos nos testes já conseguem refletir o trabalho das escolas e dos professores ao longo do período destinado à alfabetização. 
QUADRO 5 - Percentual de acerto dos itens difíceis e sua variação, segundo o nível de desempenho do grupo $-3^{\circ}$ ano do ensino fundamental

\begin{tabular}{|c|c|c|c|c|}
\hline \multirow{2}{*}{ ITEM } & \multirow{2}{*}{ HABILIDADE } & \multicolumn{2}{|c|}{$\begin{array}{l}\text { NÍVEL DE DESEMPENHO } \\
\text { DO GRUPO }\end{array}$} & \multirow{2}{*}{$\begin{array}{c}\text { DIFERENÇA } \\
\text { ENTRE OS } \\
\text { GRUPOS }\end{array}$} \\
\hline & & BAIXO & ALTO & \\
\hline P64 & Identificar o número de sílabas de uma palavra (consciência silábica). & 11,7 & 26,1 & 14,4 \\
\hline P72 & $\begin{array}{l}\text { Estabelecer relações de continuidade temática, a partir da } \\
\text { recuperação de elementos da cadeia referencial do texto. }\end{array}$ & 47,5 & 61,6 & 14,2 \\
\hline P51 & Identificar assunto de textos. & 38,3 & 51,0 & 12,7 \\
\hline P52 & Reconhecer a finalidade de gêneros diversos. & 45,6 & 57,9 & 12,3 \\
\hline P79 & Inferir informações implícitas em textos. & 33,8 & 45,9 & 12,1 \\
\hline P62 & $\begin{array}{l}\text { Identificar o efeito de sentido decorrente do uso de recursos } \\
\text { gráficos, da pontuação, da seleção lexical e repetições. }\end{array}$ & 56,4 & 67,6 & 11,2 \\
\hline P70 & Identificar efeitos de humor em textos diversos. & 44,6 & 53,9 & 9,3 \\
\hline P65 & $\begin{array}{l}\text { Identificar marcas linguísticas que evidenciam o enunciador no } \\
\text { discurso direto ou indireto. }\end{array}$ & 9,1 & 18,2 & 9,2 \\
\hline P32 & Identificar gêneros textuais diversos. & 66,2 & 74,9 & 8,7 \\
\hline P48 & $\begin{array}{l}\text { Identificar o efeito de sentido decorrente do uso de recursos } \\
\text { gráficos, da pontuação, da seleção lexical e repetições. }\end{array}$ & 52,2 & 60,8 & 8,6 \\
\hline P29 & $\begin{array}{l}\text { Identificar o efeito de sentido decorrente do uso de recursos } \\
\text { gráficos, da pontuação, da seleção lexical e repetições. }\end{array}$ & 69,7 & 78,2 & 8,5 \\
\hline P63 & Reconhecer a finalidade de gêneros diversos. & 23,4 & 31,7 & 8,3 \\
\hline P25 & Identificar assunto de textos. & 72,8 & 80,6 & 7,8 \\
\hline $\mathrm{P} 45$ & Estabelecer relações lógico-discursivas presentes no texto. & 63,4 & 70,7 & 7,3 \\
\hline P57 & $\begin{array}{l}\text { Localizar informações explícitas em textos de maior extensão ou em } \\
\text { textos que apresentam dados. }\end{array}$ & 56,4 & 63,3 & 6,9 \\
\hline P71 & Identificar gêneros textuais diversos. & 81,2 & 87,5 & 6,2 \\
\hline P78 & Identificar efeitos de humor em textos diversos. & 49,0 & 54,8 & 5,8 \\
\hline P30 & $\begin{array}{l}\text { Localizar informações explícitas em textos de maior extensão ou em } \\
\text { textos que apresentam dados. }\end{array}$ & 59,5 & 65,1 & 5,6 \\
\hline $\mathrm{P} 60$ & Inferir informações implícitas em textos & 54,9 & 60,4 & 5,5 \\
\hline P66 & $\begin{array}{l}\text { Localizar informações explícitas em textos de maior extensão ou em } \\
\text { textos que apresentam dados. }\end{array}$ & 76,0 & 81,4 & 5,4 \\
\hline P47 & Estabelecer relações lógico-discursivas presentes no texto. & 83,4 & 88,3 & 4,9 \\
\hline P77 & Reconhecer a finalidade de gêneros diversos. & 76,3 & 80,1 & 3,7 \\
\hline P56 & Estabelecer relações lógico-discursivas presentes no texto. & 68,5 & 71,9 & 3,4 \\
\hline P36 & $\begin{array}{l}\text { Localizar informações explícitas em textos de maior extensão ou em } \\
\text { textos que apresentam dados. }\end{array}$ & 38,5 & 41,4 & 2,9 \\
\hline
\end{tabular}

Fonte: Dados do Paebes-Alfa (elaboração própria)

A observação do Quadro 5 permite constatar que a variação do percentual de acerto entre as turmas de baixo e alto desempenho é bem menor que no $1^{\circ}$ ano, oscilando entre uma diferença máxima de 14,4\% e uma diferença mínima de acerto de $2,9 \%$. Isso significa que, no início do $1^{\circ}$ ano do ensino fundamental, havia maior desigualdade nas habilidades de Leitura entre as turmas. Outra observação importante é que os percentuais de acerto nos dois grupos de turmas aumentam em relação aos resultados do $1^{\circ}$ ano, ultrapassando, 
na maioria das vezes, o percentual de $60 \%$ e aproximando-se, em alguns deles, da casa de $80 \%$. Por exemplo, nos itens P25 (identificar assuntos de textos), P47 (estabelecer relações lógico-discursivas presentes no texto), P66 (localizar informações explícitas em textos de maior extensão ou em textos que apresentam dados), P71 (identificar gêneros textuais diversos) e P77 (reconhecer a finalidade de gêneros diversos), o percentual de acerto está acima de $70 \%$ para os dois grupos de desempenho, o que indica que as habilidades avaliadas por esses itens foram adquiridas pela maioria dos alunos, independentemente da turma frequentada.

É possível observar, ainda, que o item P36, que avalia a habilidade de localizar informações explícitas em textos de maior extensão ou em textos que apresentam dados, é o que tem a menor variação do percentual de acerto $(2,94 \%)$, e que esse percentual não é muito alto nas turmas de baixo e alto desempenho: $38,5 \%$ e $41,4 \%$, respectivamente.

Já o item P64, que avalia a habilidade de identificar o número de sílabas de uma palavra, tem a maior variação do percentual de acerto, e esse valor é muito baixo para os dois grupos $(11,7 \%$ nas turmas de baixo desempenho e $26,1 \%$ nas de alto). Isso revela que poucos alunos possuem essa habilidade, mesmo sendo pequena a variação entre os dois grupos. Esse item apresentou uma correlação bisserial de 0,474, indicando que ele está bem ajustado ao teste.

O item P65, utilizado na avaliação de saída no $3^{\circ}$ ano (2014), foi o único item difícil divulgado pelo Paebes-Alfa, o que possibilita sua interpretação pedagógica. O item está ancorado no padrão de desempenho avançado e possui uma correlação bisserial alta, de 0,513. 


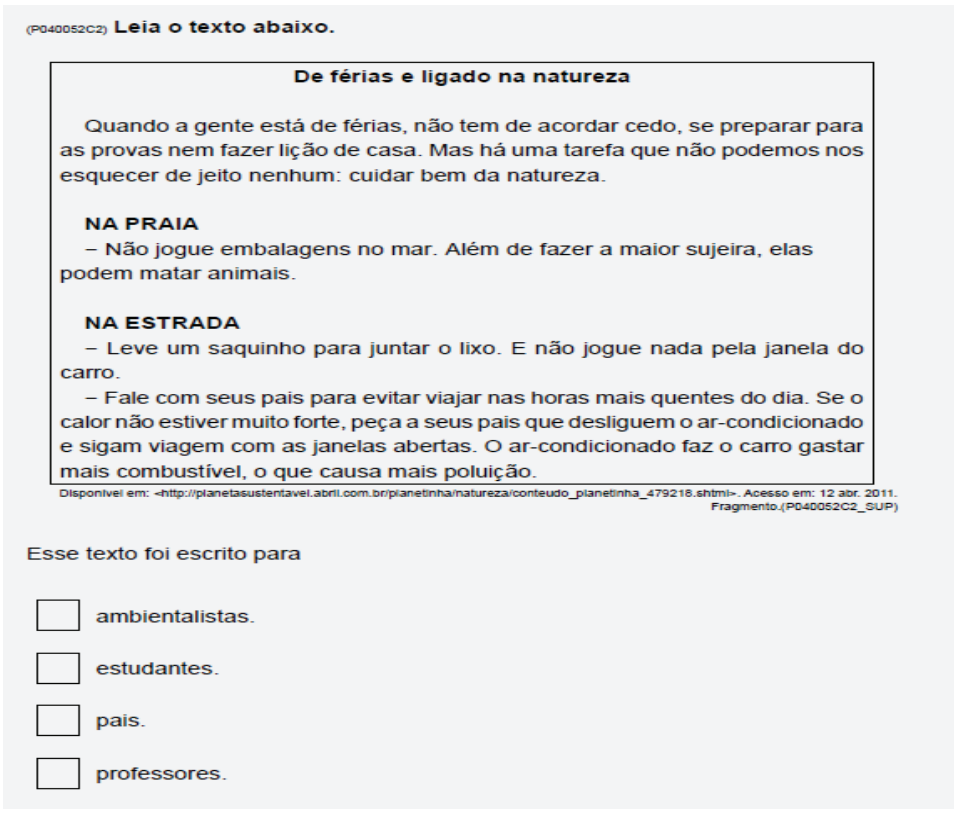

Fonte: Revista Pedagógica - Paebes-Alfa (ESPÍRITO SANTO, 2012).

Esse item, conforme pode ser observado na Figura 2, relaciona-se com a habilidade de identificar marcas linguísticas que evidenciam o enunciador no discurso direto ou indireto. $\mathrm{O}$ item exige do participante inferir, a partir de pistas linguísticas ("lição de casa”, "está de férias”, "preparar para as provas"), a quem o texto se dirige uma vez que os possíveis interlocutores não são mostrados. Tal item também avalia o uso social do texto, pois há uma finalidade e público específícos, o que faz com que os alunos precisem desenvolver outras estratégias de Leitura, para além das marcas linguísticas, a fim de conseguirem responder a questão com êxito. Esse item teve um percentual de acerto de 9,1\% nas turmas de baixo desempenho e de $18,2 \%$ nas turmas de alto desempenho, com variação entre esses dois grupos de $9,2 \%$. As baixas taxas de acerto desse item em ambos os grupos permitem aventar a hipótese de que essa habilidade tenha sido trabalhada de modo insuficiente ao longo dos três primeiros anos do ensino fundamental pelas escolas investigadas nesta pesquisa. 


\section{CONCLUSÕES}

De maneira geral, é possível dizer que, no início do $1^{\circ}$ ano do ensino fundamental, o desempenho é mais heterogêneo entre as turmas observadas na presente amostra, mas essa desigualdade vai diminuindo de forma que, ao final do $3^{\circ}$ ano, os resultados escolares são mais homogêneos. Essa tendência também é observada quando se analisam, especificamente, os itens difíceis do Paebes-Alfa. Nesse caso, quanto maior a dificuldade do item, maior a variação do acerto entre as turmas de alto e baixo desempenho nesses dois anos escolares. Apesar disso, essa variação entre os dois grupos de turmas é bem menor no $3^{\circ}$ ano, quando comparada à do $1^{\circ}$ ano.

Mesmo a variação do desempenho sendo menor entre as turmas no $3^{\circ}$ ano, algumas habilidades não foram plenamente adquiridas por nenhum dos dois grupos até o final do ciclo de alfabetização, visto que o percentual de acerto nas turmas de baixo e alto desempenho é inferior a 50\%. O Quadro 6 apresenta as habilidades com baixo percentual de acerto nos dois agrupamentos de turmas e nos anos escolares analisados.

QUADRO 6 - Habilidades que apresentaram baixo percentual de acerto nos grupos de baixo e alto desempenho nos anos avaliados

\begin{tabular}{|l|c|}
\hline \multicolumn{1}{|c|}{ HABILIDADES } & AVALIAÇÃO \\
\hline Identificar o número de sílabas de uma palavra (consciência silábica). & \multirow{2}{*}{$1^{\circ}$ e $3^{\circ}$ ano } \\
\cline { 1 - 1 } Reconhecer a finalidade de gêneros diversos. & \multirow{2}{*}{$3^{\circ}$ ano } \\
\cline { 1 - 2 } Localizar informações explícitas em textos de maior extensão ou em textos que apresentam dados. & \\
\cline { 1 - 1 } Identificar marcas linguísticas que evidenciam o enunciador no discurso direto ou indireto. & \multirow{2}{*}{$1^{\circ}$ ano } \\
\cline { 1 - 1 } Inferir informações implícitas em textos. & \\
\hline Distinguir, como leitor, diferentes tipos de letras. & \\
\hline Ler frases e pequenos textos, localizando informações explícitas. & \\
\hline Identificar assuntos de textos. & \\
\hline Reconhecer o local de inserção de determinada palavra numa sequência em ordem alfabética. & \\
\hline Identificar elementos que constroem a narrativa. & \\
\hline
\end{tabular}

Fonte: Dados do Paebes-Alfa (elaboração própria)

Trata-se claramente de habilidades básicas de Leitura, cujos percentuais de acerto evidenciam que praticamente a maioria dos alunos começa e termina o ciclo de alfabetização sem dominá-las por completo. Isso mostra a incapacidade de 
a escola trabalhar, de forma eficaz, determinados aspectos curriculares, ao mesmo tempo que nivela por baixo o desempenho da maioria de seus alunos.

Para percorrer o objetivo de promoção de justiça e eficácia, a escola precisaria pautar suas ações nos princípios da igualdade de conhecimento, o que pressupõe que as formas de organização escolar deveriam priorizar o aprendizado dos conhecimentos de base para todos os estudantes.

Se essa perspectiva indica que as ações escolares e as práticas pedagógicas precisam ser planejadas em função de objetivos a serem atingidos por todos, as análises realizadas neste estudo com dados do Paebes-Alfa permitem depreender que os princípios da igualdade de conhecimento não se concretizam. Nesse caso, os alunos das turmas de alto e baixo desempenho não consolidam parte dos conhecimentos de base referentes à etapa da alfabetização, o que pode comprometer a aquisição de outros conhecimentos e o desenvolvimento de aprendizagens futuras da maioria dos alunos.

\section{REFERÊNCIAS}

ALVES, M. T. G.; FRANCO, C. A pesquisa em eficácia escolar no Brasil: evidências sobre o efeito das escolas e fatores associados à eficácia escolar. In: BROOKE, N.; SOARES, J. F. (Org.). Pesquisa em eficácia escolar no Brasil: origem e trajetórias. Belo Horizonte: Editora UFMG, 2008. p. 483-502.

BRASIL. Constituição (1988) da República Federativa do Brasil. Diário Oficial da União [da] República Federativa do Brasil, Brasília, DF, 5 out. 1988.

BRASIL. Lei n. 11.274, de 6 de fevereiro de 2006. Altera a redação dos arts. 29, 30, 32 e 87 da Lei n. 9.394, de 20 de dezembro de 1996, que estabelece as diretrizes e bases da educação nacional, dispondo sobre a duração de 9 (nove) anos para o ensino fundamental, com matrícula obrigatória a partir dos 6 (seis) anos de idade. Diário Oficial da União [da] República Federativa do Brasil, Brasília, DF, 7 fev. 2006. Disponível em: <www.planalto.gov.br/ccivil_03/_Ato2004- 2006/2006/Lei/L11274.htm>. Acesso em: maio 2016.

CARVALHO, M. P. Sucesso e fracasso escolar: uma questão de gênero. Educação e Pesquisa, São Paulo, v. 29, n. 1, p. 185-193, jun. 2003.

CRAHAY, M. Poderá a escola ser justa e eficaz? Da igualdade de oportunidades à igualdade de conhecimentos. Tradução de Vasco Farinha. Lisboa: Instituto Piaget, 2002. 
ESPÍRITO SANTO. Secretaria de Educação. Revista Pedagógica do Paebes-Alfa 2012, Juiz de Fora, 2012. Disponível em: <http://www.paebes.caedufjf. net/wp-content/uploads/2013/06/PAEBES_Alfa_RPEDAGOGICA_LP_ MAT_2EF_2012.pdf>. Acesso em: 30 nov. 2016.

ESPÍRITO SANTO. Secretaria de Educação. Paebes - 2013, Juiz de Fora, v. 2, jan./dez. 2013. Disponível em: <http://www.paebes.caedufjf.net/wp-content/ uploads/2014/07/PAEBES-RG-RE-WEB.pdf>. Acesso em: 30 nov. 2016.

ESPÍRITO SANTO. Secretaria de Educação. Paebes Alfa - 2014, Juiz de Fora, v. 1, jan./dez. 2014. Disponível em: < http://www.paebesalfa2onda.caeduff. net/wp-content/uploads/2015/04/PAEBES-ALFA-2014-RP-LP_MT-3EF_WEB.pdf>. Acesso em: 30 nov. 2016.

FRANCO, C. et al. Qualidade e equidade na educação fundamental brasileira, 2002. Disponível em: <http://www.econ.puc-rio.br/pdf/td455.pdf>. Acesso em: 10 ago. 2016.

HAMBLETON, R. et al. Fundamentals of item response theory. Newbury Park: Sage Publications, 1991.

HOGAN, T. Introdução à prática de testes psicológicos. Rio de Janeiro: LTC, 2006.

MISLEVY, D.; BOCK, R. Bilog: Item analysis and test scoring with binary models. Chicago: Scientific Software, 1990.

RAUDENBUSH, S. W.; BRYK, A. S. Hierarchical Linear Models. 2nd. ed. Thousand Oaks: Sage, 2002.

RIBEIRO, V. Que princípios de justiça para a Educação Básica? Cadernos de Pesquisa, São Paulo, v. 44, n. 154, p. 1.094-1.109. out./dez. 2014.

SOARES, J. F.; ALVES, M. T. G. Desigualdades raciais no sistema brasileiro de educação básica. Educação e Pesquisa, São Paulo, v. 29, n. 1, p. 147-165, jan.jjun. 2003.

SOARES, J. F.; ANDRADE, R. Nível sócio-econômico, qualidade e equidade das escolas de Belo Horizonte. Ensaio: Avaliação de Políticas Públicas Educacionais, Rio de Janeiro, v. 14, n. 50, p. 107-126, jan./mar. 2006.

XAVIER, F. P.; ALVES, M. T. G. A composição social importa para os efeitos das escolas no ensino fundamental? Estudos em Avaliação Educacional, São Paulo, v. 26, n. 61, p. 216-243, jan./abr. 2015.

\section{NAIRA DA COSTA MUYLAERT LIMA}

Pós-doutoranda do Departamento de Educação da Pontifícia Universidade Católica do Rio de Janeiro (PUC-Rio), Rio de Janeiro, Rio de Janeiro, Brasil naira.muylaert@hotmail.com 
ALICIA MARIA CATALANO DE BONAMINO

Professora do Departamento de Educação da Pontifícia Universidade Católica do Rio de Janeiro (PUC-Rio), Rio de Janeiro, Rio de Janeiro, Brasil

alicia@puc-rio.br

\section{LUIS ANTONIO FAJARDO PONTES}

Analista de dados sênior do Centro de Políticas Públicas e Avaliação da Educação da Universidade Federal de Juiz de Fora (CAEd/UFJF), Juiz de Fora, Minas Gerais, Brasil luis@caed.ufjf.br 
